\title{
An Experimental Study on Low-Calcium Flyash and Metakaolin Based Geo-Polymer Concrete
}

\author{
Rakesh Kumar Gupta ${ }^{1}$, Dr. Rajeev Chandak ${ }^{2}$ \\ ${ }^{1} \mathrm{ME}$ (Structure Engineering), ${ }^{2}$ Prof. and Head, \\ Department of Civil Engineering, Jabalpur Engineering College, Jabalpur, Madhya Pradesh, India
}

\begin{abstract}
Geo-polymer concrete is known as one of environmental- friendly construction materials. Using by-product material such as flyash and metakaolin replace cement would avoid carbon dioxide $(\mathrm{CO} 2)$ emission during the manufacturing process of ordinary Portland cement (OPC). The objective of his research work was to produce a carbon dioxide emission free cementious material. This paper discusses low-calcium Flyash and metakaolin based geo-polymer concrete with different proportion of binder and molarities. The alkaline liquids used in this study for the polymerization are the solutions of Sodium hydroxide $(\mathrm{NaOH})$ and sodium silicate (Na2Sio3). In this paper variation of source material for low-calcium Fly ash and Metakaoline and at various molarities like $10 \mathrm{M}, 12 \mathrm{M}$ and $14 \mathrm{M}$ is done to achieve compressive strength for medium grade of concrete of M-25. They are curing by oven at $600 \mathrm{C}$ for 24 hours then after ambient temperature. It is found that geo-polymer concrete with Metakoline and low-calcium Fly ash as increase its strength and shows good strength with increase in the molarity of the alkaline solution also comparable with that of Ordinary portland cement concrete.
\end{abstract}

Keyword: Geo-polymer concrete, PCC, Alkaline solution, flyash, metakaolin, cement, compressive strength.

\section{INTRODUCTION}

The term geo-polymer was first coined by Davidovits in 1978 to represent a broad range of materials characterized by chains or networks of inorganic molecules. Geo-polymers are chains or networks of mineral molecules linked with co-valent bonds. Geopolymer is produced by a polymeric reaction of alkaline liquid with source material of geological origin or by product material such as fly ash, rice husk ash, GGBS etc. Because the chemical reaction that takes place in this case is a polymerization process, Davidovits coined the term 'Geo-polymer' to represent these binders. Geo-polymers have the chemical composition similar to Zeolites but they can be formed an amorphous structure. He also suggested the use of the term 'poly (sialate)' for the chemical designation of geo-polymers based onsilicoaluminate. Sialate is an abbreviation for silicon-oxo aluminate.

There is associate degree increasing interest within the use of geopolymer concrete shows the new path of reusing waste materials and to scale back the adverse effects on the environment. Geopolymer concrete products are best-known to possess much better sturdiness and strength properties than OPC concrete. These properties are investigated extensively in laboratory to verify and ensure the superior sturdiness and strength properties. The investigation conjointly discusses the factors that prohibit the utilization of geopolymer concrete as another to opc concrete and conjointly source of geopolymer concrete. Laboratory tests are conducted on compressive strength, split tensile and flexural tests for specimens with different pozzolanic material primarily based geopolymer concrete and combination of various concentration of molarity.

\section{LITERATURE REVIEW}

Djwantoro Hardjito (2004) studied that the contribution of Portland cement production worldwide to the greenhouse gas emission is about 1.35 billion tons per annum or about $7 \%$ of the total greenhouse gas emissions to the earth "s environment. Cement is also one among the most energy-intensive 
construction materials, after aluminum and steel. It also, reported that the durability of ordinary Portland cement (OPC) concrete is under examination, as many concrete structures, especially those built in corrosive environments, even though they have been designed for more than 50 years of service life; start to deteriorate after 20 to 30 years.

Osman Sinik (2016) conducted a study by mixing fly ash, sodium silica solution, $\mathrm{NaOH}$, kaolinite, and water to produce Geopolymer. The compressive strength was affected by both the curing temperature and the curing time, and the optimum strength occurred when Specimens were cured at $60^{\circ} \mathrm{C}$ for a period of 24 hours.

Hai Yan Zhang (2014) investigated that in the past Fly ash has been used to replace partially for Portland cement to produce concretes. An important achievement in this regard is up to 60 percent of fly ash was replaced for OPC for the development of high volume fly ash (HVFA) concrete yet possesses excellent mechanical properties with enhanced durability performance. The test results performed well and it shows that HVFA concrete is more durable than ordinary Portland cement concrete.

S. K. Bhattacharyya (2015) reported the study of fly ash-based Geopolymers. They used both the combinations of sodium hydroxide with sodium silicate and potassium hydroxide with potassium silicate as alkaline liquids. It was established that the type of alkaline liquid is a noteworthy factor affecting the mechanical strength, and that the combination of sodium silicate and sodium hydroxide shows the appreciable highest compressive strength.

\section{PROPERTIES OF MATERIALS USED FOR THE STUDY}

The following materials have been used in the experimental study:-

3.1.1 Metakaolin:- Metakaolin is one of the most abundant natural minerals which produced by heattreating kaolin. It is highly reactive metastable clay that is an anhydrous aluminosilicate obtained from calcining kaolin to around $650-700^{\circ} \mathrm{C}$. There are physical properties are:-

$\begin{array}{ll}\text { Physical properties } & \text { Values } \\ \text { Specific gravity } & 2.5 \\ \text { Mean grain Size }(\boldsymbol{\mu m}) & 2.54 \\ \text { Specific area } \mathbf{c m} 2 / \mathbf{g m} & 120000-180000 \\ \text { Colour } & \text { White } \\ \text { Physical form } & \text { powder }\end{array}$

3.1.2 Fly Ash (low-calcium) collected form Sanjay Gandhi Thermal power plant Brishinghpur pali (M.P.) having specific gravity 2.21 .

\section{Table chemical composition of flyash}

\begin{tabular}{lll} 
S. No. & $\begin{array}{l}\text { Elemental } \\
\text { oxides }\end{array}$ & Percentaage \\
\hline $\mathbf{1}$ & $\mathrm{SiO}_{2}$ & 53.14 \\
$\mathbf{2}$ & $\mathrm{Al}_{2} \mathrm{O}_{3}$ & 25.88 \\
$\mathbf{3}$ & $\mathrm{Fe}_{2} \mathrm{O}_{3}$ & 3.14 \\
$\mathbf{4}$ & $\mathrm{TiO}_{2}$ & 1.51 \\
$\mathbf{5}$ & $\mathrm{CaO}$ & 0.34 \\
$\mathbf{6}$ & $\mathrm{MgO}$ & 1.13 \\
$\mathbf{7}$ & $\mathrm{NaO}_{2}$ & 1.19 \\
$\mathbf{8}$ & $\mathrm{K}_{2} \mathrm{O}$ & 1.22 \\
$\mathbf{9}$ & $\mathrm{SO}_{3}$ & 0.53 \\
$\mathbf{1 0}$ & $\mathrm{P}_{2} \mathrm{O}_{5}$ & 1.65 \\
\hline
\end{tabular}

3.1.3 Cement (OPC43 GRADE) Cement must develop the appropriate strength. It must represent the appropriate rheological behavior.
Physical Properties

Normal consistency

Initial setting time (mint.)

Final setting time (mint.)

Specific gravity

Colour

\section{Test Result}

$29 \%$

$45 \mathrm{mint}$

$350 \mathrm{mint}$

3.148

gray
3.1.4 Fine aggregate: Sand confirming to Zone of IS: 383-1970 and some other physical properties are:-

\begin{tabular}{|ll|}
\hline Physical Properties & Test Result \\
\hline Zone of Fine aggregate & Zone-II \\
\hline Specific gravity & 2.66 \\
\hline$\%$ of moisture & $0.8 \%$ \\
\hline Fineness modulus & 2.95 \\
\hline Source & Narmada River \\
\hline
\end{tabular}


International Journal of Trend in Scientific Research and Development (IJTSRD) ISSN: 2456-6470

3.1.5 Coarse aggregate: As per code IS:383-1970 having properties of aggregate.

\begin{tabular}{|ll|}
\hline Physical Properties & Test Result \\
\hline Specific gravity(10\&20mm) & 2.86 \\
\hline \% of moisture & $0.3 \%$ \\
\hline Fineness modulus(10\&20mm) & $6.12 \& 7.05$ \\
\hline Source & Jabalpur \\
\hline
\end{tabular}

3.2 Alkaline activators:- To activate the fly ash a combination of sodium hydroxide solution and sodium silicate solution was chosen as the alkaline activator. The sodium hydroxide used was a technical grade sodium hydroxide in pellets form with a specific gravity of $2.1 \& 98 \%$ purity and obtained from LOBA chemical. The mass of $\mathrm{NaOH}$ solids in a solution varied depending on the concentration of the solution expressed in terms of molar (M).

\section{Properties of Sodium hydroxide ( $\mathrm{NaOH})$}

\section{Molar mass}

Appearance

Density

Mealting point

Boiling point

Amount of heat liberates

when dissolved in water

\section{$40 \mathrm{gm} / \mathrm{mol}$}

White solid

$2.1 \mathrm{gm} / \mathrm{cc}$

$310^{\circ} \mathrm{C}$

$1390^{\circ} \mathrm{C}$

$266 \mathrm{cal} / \mathrm{gm}$

\section{Mix Design of Geopolymer Concrete:-}

In the design of geopolymer concrete mix, coarse and fine aggregates together were taken as $78 \%$ of entire mixture by mass. This value is similar to that used in OPC concrete in which it will be in the range of 75 to $80 \%$ of the entire mixture by mass. Fine aggregate was taken as $35 \%$ of the total aggregates. Taking into consideration the workability, the ratio of sodium silicate to sodium hydroxide solution was kept 2.5. The density of geo-polymer concrete is taken similar to that of OPC as $2400 \mathrm{~kg} / \mathrm{m} 3$. The details of mix design and its proportions for different grades of GPC are given in Table.

\begin{tabular}{|c|c|c|c|c|c|c|c|c|}
\hline \multirow[t]{2}{*}{ MIX } & \multirow{2}{*}{$\begin{array}{l}\text { Fly } \\
\text { ash }\end{array}$} & \multirow[t]{2}{*}{ MK } & \multicolumn{2}{|l|}{ C.A. } & \multirow[t]{2}{*}{ F.A. } & \multirow{2}{*}{$\begin{array}{l}\mathrm{NaOH} \\
+ \\
\mathrm{Na}_{2} \mathrm{SiO}_{3}\end{array}$} & \multirow{2}{*}{$\begin{array}{l}\text { ALK./ } \\
\text { BIN. }\end{array}$} & \multirow[t]{2}{*}{ SP. } \\
\hline & & & 20MM & 10MM & & & & \\
\hline $\mathbf{G C}_{1}$ & 328.5 & 36.5 & 852 & 365 & 655 & 163 & 0.45 & $2 \%$ \\
\hline $\mathbf{G C}_{2}$ & 292 & 73 & 852 & 365 & 655 & 163 & 0.45 & $2 \%$ \\
\hline $\mathbf{G C}_{3}$ & 255.5 & 109.5 & 852 & 365 & 655 & 163 & 0.45 & $2 \%$ \\
\hline $\mathrm{GC}_{4}$ & 328.5 & 36.5 & 852 & 365 & 655 & 163 & 0.45 & $2 \%$ \\
\hline $\mathbf{G C}_{5}$ & 292 & 73 & 852 & 365 & 655 & 163 & 0.45 & $2 \%$ \\
\hline GC $_{6}$ & 255.5 & 109.5 & 852 & 365 & 655 & 163 & 0.45 & $2 \%$ \\
\hline $\mathbf{G C}_{7}$ & 328.5 & 36.5 & 852 & 365 & 655 & 163 & 0.45 & $2 \%$ \\
\hline $\mathbf{G C}_{8}$ & 292 & 73 & 852 & 365 & 655 & 163 & 0.45 & $2 \%$ \\
\hline $\mathbf{G C}_{9}$ & 255.5 & 109.5 & 852 & 365 & 655 & 163 & 0.45 & $2 \%$ \\
\hline $\mathrm{CC}_{10}$ & 365 & & 852 & 365 & 655 & 163 & 0.45 & \\
\hline
\end{tabular}

\section{Preparation, Casting and Curing of Geopolymer Concrete:-}

The alkaline activator solution used in GPC mixes was a combination of sodium hydroxide solution, sodium hydroxide pellets and distilled water. The role of alkaline activator solution is to dissolve the reactive portion of source materials $\mathrm{Si}$ and $\mathrm{Al}$ present in fly ash and provide a high alkaline liquid medium for condensation polymerization reaction. To prepare sodium hydroxide solution of 10,12 , and 14 molarity (M) such as 400g, 480g, and $560 \mathrm{~g}$ of sodium hydroxide pellets was dissolved in water. The mass of $\mathrm{NaOH}$ solids in a solution will vary depending on the concentration of the solution expressed in terms of molar (M). The pellets form of $\mathrm{NaOH}$ are dissolved in one liter of water for the required concentration. When sodium hydroxide and sodium silicate solutions mixed together polymerization will take place liberating large amount of heat, which indicates that the alkaline liquid must be used after 24 hours as binding agent. Geopolymer concrete can be manufactured by adopting the conventional techniques used in the manufacture of Portland cement concrete. In the laboratory, the fly ash \& metakaolin and the aggregates were first mixed together dry on pan for about three minutes. The liquid component of the mixture is then added to the dry materials and the mixing continued usually for another four minutes. The addition of sodium silicate is to enhance the process of geopolymerization. For the present study, concentration of $\mathrm{NaOH}$ solution are taken as $10 \mathrm{M}, 12 \mathrm{M}$, and $14 \mathrm{M}$ with varying ratio of $\mathrm{Na}_{2} \mathrm{SiO}_{3} / \mathrm{NaOH}$ as 2.5 for all the grades of Geopolymer concrete mixes. The workability of the fresh concrete was measured by means of conventional slump test. In order to improve the workability, super plasticizer with a dosage of $2.0 \%$ by mass of the fly ash \& Metakaolin was added to the 
mixture. Extra water (other than the water used for the preparation of alkaline solutions) and dosage of super plasticizer was added to the mix according to the mix design details. The fly ash \& Metakaolin and alkaline activator were mixed together in the mixer until homogeneous pate was obtained. This mixing process can be handled with in 10 to 15 minutes for each mixture with different ratios of alkaline solution. The entire specimen transferred to oven set at $60^{\circ} \mathrm{C}$ and stored for 24 hours then after ambient temperature. Both curing time and curing temperature influence the compressive strength of Geopolymer concrete. After casting the specimens, they were kept in rest period for two days and then they were demoulded. The demoulded procedure is similar to that of routine conventional concrete.

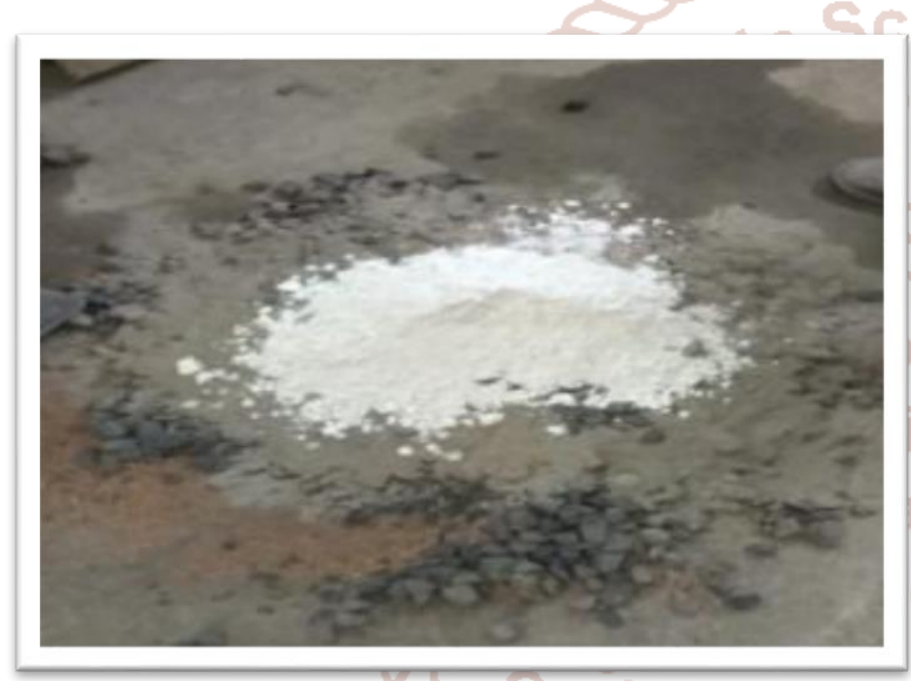

Fig. preparation of geopolymer concrete mix

\section{RESULTS AND DISCUSSIONS:-}

\subsection{Workability:-}

The workability of concrete mixes was found out by slump test as per procedure. Liquid/binder ratio was kept constant 0.45 for all the concrete mixes. Superplasticizer was used to maintain the required slump. Dosage of super-plasticizer was maintained $2 \%$ by weight of binder on all type of mix. It present the results of the effect of the molarity of alkaline activator on workability of different concrete mixes. The addition of metakolin to concrete mix increase, the workability of concrete mix was found to decrease as compared to control mix of flyash. The addition of metakaolin into concrete mix further decreases the workability. The slump value of all mix varies between $90-110$.

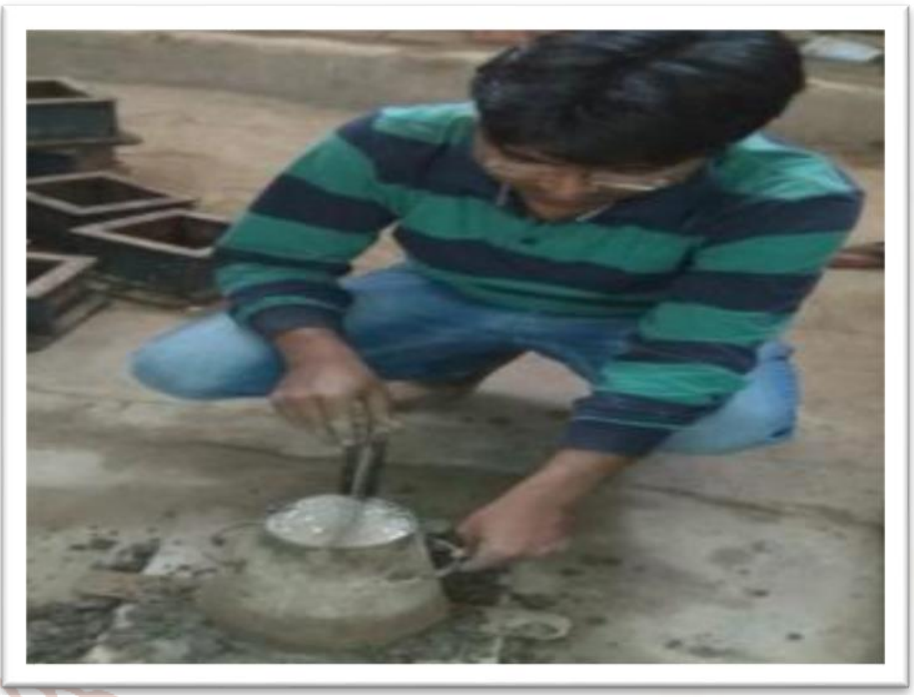

Fig. slump cone apparatus

\subsection{Compressive strength:-}

The results of the compressive strength tests conducted on geopolymer concrete specimens of different mixes cured at different ages are presented,

\begin{tabular}{|c|c|c|c|c|}
\hline Mix & Molarity & Discription & $\begin{array}{l}7 \\
\text { DAYS }\end{array}$ & $\begin{array}{l}28 \\
\text { DAYS }\end{array}$ \\
\hline $\mathbf{G C}_{1}$ & $10 \mathrm{M}$ & $90 \% \mathrm{FA}+10 \% \mathrm{MK}$ & 18.42 & 27.34 \\
\hline $\mathbf{G C}_{2}$ & $10 \mathrm{M}$ & $80 \% \mathrm{FA}+20 \% \mathrm{MK}$ & 18.78 & 27.91 \\
\hline $\mathbf{G C}_{3}$ & $10 \mathrm{M}$ & $70 \% \mathrm{FA}+30 \% \mathrm{MK}$ & 19.03 & 28.36 \\
\hline $\mathbf{G C}_{4}$ & $12 \mathrm{M}$ & $90 \% \mathrm{FA}+10 \% \mathrm{MK}$ & 20.53 & 29.87 \\
\hline GC5 & $12 \mathrm{M}$ & $80 \% \mathrm{FA}+20 \% \mathrm{MK}$ & 20.86 & 30.54 \\
\hline GC $_{6}$ & $12 \mathrm{M}$ & $70 \% \mathrm{FA}+30 \% \mathrm{MK}$ & 21.22 & 31.09 \\
\hline $\mathrm{GC}_{7}$ & $14 \mathrm{M}$ & $90 \% \mathrm{FA}+10 \% \mathrm{MK}$ & 22.69 & 32.44 \\
\hline GC8 & $14 \mathrm{M}$ & $80 \% \mathrm{FA}+20 \% \mathrm{MK}$ & 22.88 & 32.95 \\
\hline GC9 & $14 \mathrm{M}$ & $70 \% \mathrm{FA}+30 \% \mathrm{MK}$ & 23.14 & 33.27 \\
\hline $\mathrm{CC}_{10}$ & - & OPC 43 GRADE & 22.53 & 31.92 \\
\hline
\end{tabular}

Where FA and MK are stands for Flyash and Metakaolin for different molarity also graphical representation on compressive strength vs mixing ratio of all mix are shows below

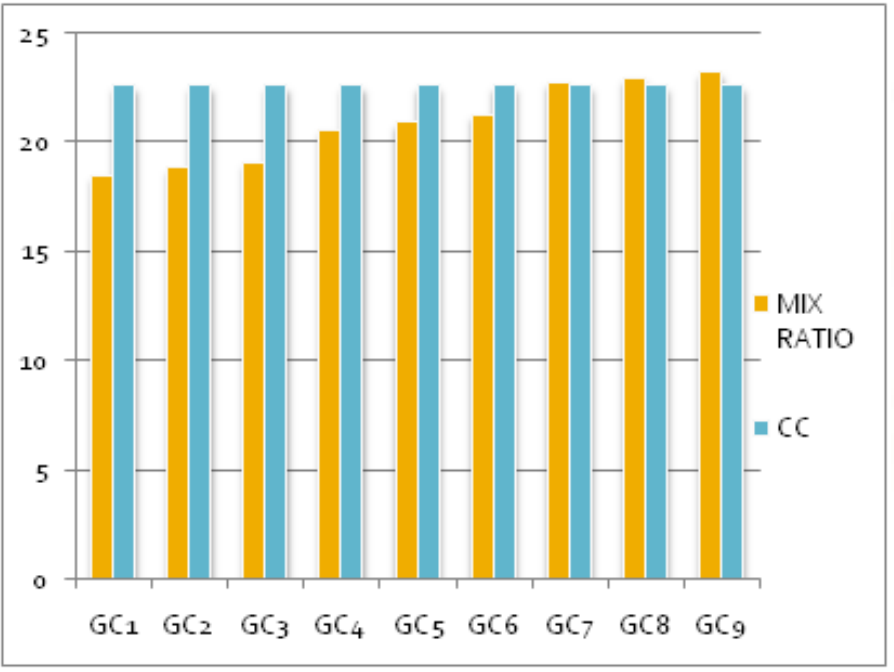

Figure 1Compressive strength of specimens at the age of 7 days 


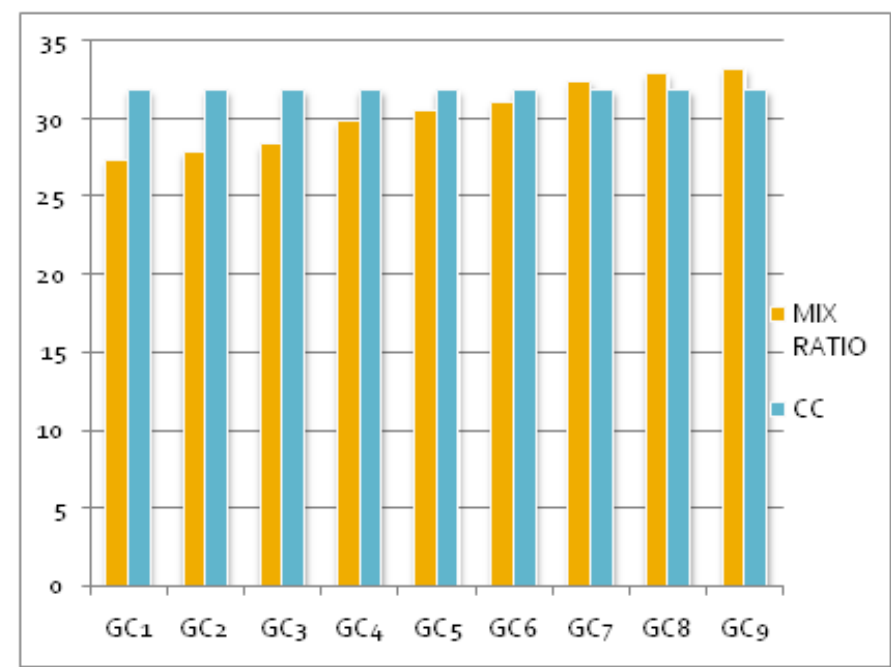

Figure2 Compressive strength of specimens at the age of 28 days

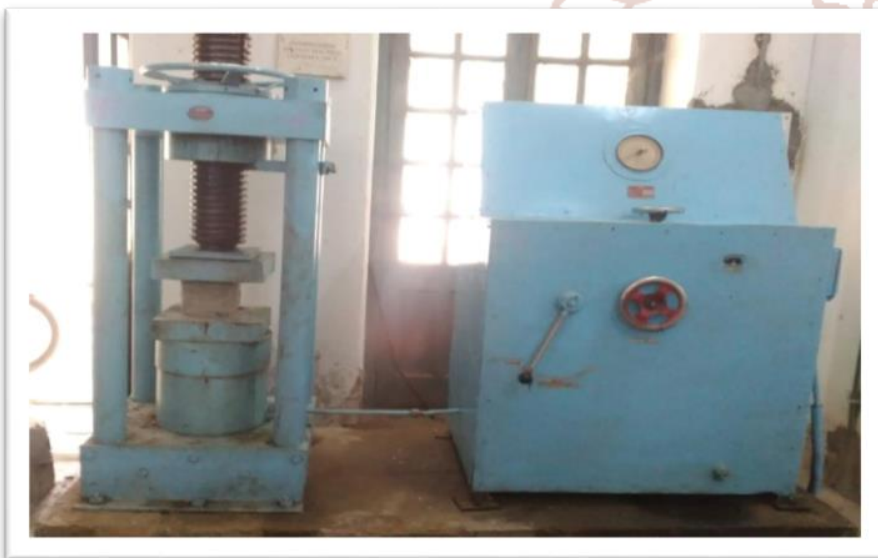

Fig. compression test apparatus

\section{Conclusion:-}

Based on the experimental work reported in this study the following conclusions are drawn:-

1. The addition of metakolin to concrete mix increase the workability of concrete mix was found to decreases as compared to control mix of flyash.

2. Higher concentration (in terms of molar) of sodium hydroxide solution results in higher compressive strength of fly ash \& metakaolin based geo-polymer concrete.

3. In addition to that fly ash shall be effectively used and hence no landfills are required to dump the fly ash

4. Geopolymer concrete has excellent properties within both acid and salt environments comparing to OPC the production of geopolymer have a relative higher strength and better durability.
5. We observe that the compressive strength is increased with the increase in the molarity of the sodium hydroxide.

6. Geopolymer concrete made with $30 \%$ metakaolin and $70 \%$ flyash with $14 \mathrm{M}$ of $\mathrm{NaOH}$ provide optimum compressive strength as that of OPC specimens.

\section{REFERENCES:-}

1. Hai Yan Zhang, Venkatesh kodur, Shu LIang Qi, and LIang Cao (2014),"Development of metakaoli-flyash based geopolymer for fire resistance application" PP 38-45.

2. Djwantoro Hardjito, Steenie E. Wallah, Dody M. j. Sumajouw and B. Vijayan Rangan (2004) "On the development of flyash based geopolymer concrete". ACI journal V. 101 No. 6.

3. F. N. Okoye, J. Durgaprasad, N. B. Singh (2015) "Flyash/ Kaolin based geopolymer green concretes and their mechanical properties" pp. 739-744.

4. B. Singh, Iswarya g., M. Gupta and S. K. Bhattacharyya (2015) "Geopolymer concrete: A review of some recemt developments" pp. 78-90.

5. Diaz-Loya EI, Allouche EN, Vaidya S., (2011), "Mechanical properties of fly ash-based geopolymer concrete". ACI Mater J; 108:300-6.

6. Muhd Fadhil Nurruddin, Sani Haruna, Bashar S. Mohammed and Ibrahim Galal Sha aban (2017) "A review: Method of curing geopolymer concrete" pp. 31-36.

7. Djwantoro Hardjito, Chua Chung cheak \& Carrie Ho Lee Ing (2009) " Strength and setting Time of Low Calcium Flyash based Geopolymer Mortar" vol. 2 No. 04

8. Gokhan Gorhan, Ridvan Aslaner and Osman Sinik (2016) "The effect of curng on the Properties of metakaolin and flyash based geopolymer paste" PP. 329-335.

9. Malhotra, V. M., "High-Performance HighVolume Fly Ash Concrete,"Concrete International, V. 24, No. 7, July 2002, pp. 1-5.

10. Peem Nuaklong, Vanchai Sata and Prinya Chindaprasirt (2017) "Properties of metakaolinhigh calcium fly ash geopolymer concrete containing recycled aggregate from crushed concrete specimens" PP. 365-373.

11. Zhang Z., a, Wanga H., Zhu Y. a, Reid A., b, John L., Provis c, d, Bullena. F., (2014), "Using fly ash to partially substitute metakaolin in geopolymer synthesis”, Applied Clay Science 88-89, 194-201. 